\title{
Security of infrastructural linear objects by using three-dimensional laser scanning technology
}

\author{
Dmitry Gura ${ }^{1,2 *}$, Alina Pavlyukova ${ }^{1,2}$, and Georgy Akopyan ${ }^{1}$ \\ ${ }^{1}$ Kuban State Technological University, Moskovskaya, 2, Krasnodar, 350072, Russia \\ ${ }^{2}$ Kuban State Agrarian University, Kalinina, 13, Krasnodar, 350044, Russia
}

\begin{abstract}
For the functioning of any social infrastructure object, power supply is necessary. Therefore, such linear real estate objects as power lines are important elements in the urban engineering infrastructure. Linear objects are characterized by a considerable length, which makes it difficult to perform certain types of work, including monitoring. This paper discusses the structural elements of the overhead power lines (OHPL) and their inherent types of deformations. Current methods for monitoring and the instruments used are indicated. The disadvantages of the existing technology are described, which include bias data, a low degree of immediacy of its receipt, complexity, risk to the health of the performer. Alternative contact methods (using various sensors) and remote monitoring methods (video recording) with an indication of their shortcomings are analyzed. A scanning complex was performed, the results of which examined the possibility of using this technology as a strain monitoring using the example of supports and wires of overhead power lines. To do this, in laboratory conditions, measurements of the support tilting, the height of the suspension, the sag of the span, the size of the wire, and the length of the span were made for compliance with regulatory data. A conceptual basis for creating an urban digital monitoring platform for a network of power lines is proposed.
\end{abstract}

\section{Introduction}

The modern city is a combination of social and engineering infrastructure. The first include buildings designed to ensure the livelihoods of citizens, for example, houses, hospitals, shops, universities, schools, and the second - structures that ensure the functioning of the previous ones. For the functioning of any social infrastructure facility, electricity is needed. In this regard, important elements in the urban engineering infrastructure are power lines, which are divided into overhead and cable ones. This paper discusses overhead power lines (OHPL).

These objects are subject to deformation due to the impact of natural (weather, vegetation) and anthropogenic factors (unintentional or intentional damage to supports,

\footnotetext{
${ }^{*}$ Corresponding author: gda-kuban@mail.ru
} 
non-compliance with technical standards during the construction of structures, illegal actions within the protective zone). Deformations can lead to an emergency blackout in social infrastructure facilities, as well as become a threat to the safety of life of citizens who are in the zone of damage. In this regard, there is a need to monitor the condition of overhead line structures in order to identify deformations, eliminate them and prevent accidents.

Nowadays, overhead power lines are monitored by visual inspection and measurement of structural parts: supports, foundations, lightning protection cables, wires, guy wires, linear insulation, grounding devices, linear fittings and others (in accordance with the guidelines used in the Russian Federation).During the inspection, the following can be revealed: tilts, deformations of supports and their individual elements from the design position, sags, a decrease in the cross section of the design elements as a result of corrosion of metal elements. In this case, measurements are carried out using a caliper, a measuring ruler, a tape measure (for measuring the linear dimensions of individual structural elements, distances), a theodolite (determination of deviations of struts of supports, spans of wire sag), steel wire with a diameter of $1 \mathrm{~mm}$ (curvature of structural elements), an insulating rod.

The existing monitoring method has several disadvantages:

- subjectivity of the survey (the performer visually determines the damage first, and then proceeds to measure them);

- complexity (inspection, measurement, processing of extended objects);

- low efficiency of data collection;

- health risk to the performer.

In the scientific literature, there are a number of developments on alternative monitoring methods, which, depending on the degree of remoteness of OHPL measuring instruments, can be divided into three groups: remote, contact, combined.

Remote methods include the magnetometric method (determines the defect of the metal), the optical method based on video recording (control of the deviation of the top of the support, measuring the size of the phase wires), as well as thermal imaging, measuring defects using robotic total stations, laser scanning [1-9]. The contact method is the tensometric method (the study of icy-wind effects), the use of capacitive sensors (monitoring the presence and thickness of the ice wall), inclinometers (for example, Nivel 210, Nivel 220), which make it possible to determine the inclination of the support from the vertical axis [10-13]. The combined method - mathematical modeling (modeling wire sag based on sensor data).

The disadvantages of each method will be discussed below. However, all the studied scientific papers are characterized by the lack of automated data processing, as well as by an abstract presentation of the monitoring method without elaborating further use of the data, for example, within the framework of a large-scale geoinformation monitoring database.

In this paper, we will consider the remote method of three-dimensional laser scanning with the elaboration of the conceptual foundations of creating a monitoring system for a database of urban electric grid infrastructure.

The main terms used in the paper:

1. Power line deformations - deviations of structural elements such as supports, racks, wires, insulators from regulatory and technical standards;

2. Monitoring of infrastructure facilities - a system for monitoring the state of structural elements for their compliance with regulatory and technical parameters;

3. Point cloud - a set of points of scanned objects located in the radius of the survey;

4. Power line - a system of energy equipment designed to transmit electricity through electric current; 
5. The height of the line suspension - the distance from the ground to the place of attachment of the wire on the insulator of the support;

6. Sag - the distance in the vertical plane from the lowest point of the wire in the span to a straight line between the points of attachment of the wire to the supports;

7. The size of the wire above the ground is the distance from the wires to the surface of the earth with the largest sag;

8. Digital monitoring platform - a hybrid information resource that allows algorithmizing the relationship of a significant number of users of monitoring information.

\section{Methods}

A measurement method was chosen for the study. The measuring tool is the Leica Scanstation C10 ground-based laser scanner, which was verified before the survey and meets all accuracy requirements (Fig. 1). The device has a two-axis compensator, a full field of view (horizontal 360, vertical 270), a built-in video camera and a laser plummet [14].

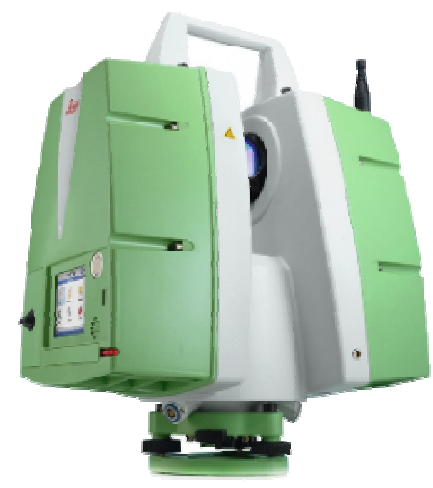

Fig. 1. Leica ScanStation C10 scanner, Source: https://geosystems.ru

The measurement technology is three-dimensional laser scanning, which consists in high-speed measurement of distances, as well as horizontal and vertical angles from the scanner to points of terrain $[15,16]$. The results of scanning are recorded in the memory of the device in the form of a point cloud - a set of measured points with known threedimensional coordinates (XYZ), which allows getting a detailed digital spatial double of objects located in the radius of the survey. For this instrument, this value is $300 \mathrm{~m}$. The distance for the Leica Scanstation C10 is measured with an accuracy of $4 \mathrm{~mm}$ at $50 \mathrm{~m}$, the vertical and horizontal angle is $12^{\prime \prime} / 12^{\prime \prime}$, and a single location is $6 \mathrm{~mm}$ [17].

To obtain a more detailed measurement result, the discreteness value was set to $5 * 5 \mathrm{~cm}$ per $100 \mathrm{~m}$, in 1 second the device recorded 50,000 points. Other set shooting parameters were: shooting mode - everything, exposure - automatic, shutter speed $64 \mathrm{~s}$, recording uncompressed, resolution - $1920 * 1920$.

The measurement technology included a field and laboratory stages. The field scanning stage consisted of the following:

1. Reconnaissance survey of the area. As a result of the study of the survey area, 12 points of scanner location (stations) and 6 points of location of the marks were selected. The main criterion for the selection of such points was the mutual visibility and overlap of the point clouds of each station, for subsequent stitching at the laboratory stage; 
2. Installing the scanner at the designed point, centering the device;

3. Arrangement of marks on a tripod and their centering, determination of coordinates and heights;

4. Ground laser scanning. The operating time at one station was 20 minutes;

5. Moving the instrument to the next scan point and repeating steps 2-5.

The laboratory stage was the processing of measurements and consisted of importing point clouds, photos from each station into the Leica Cyclone 9.4 program, registering the project, and stitching the scans of each station by marks. As a result, a general threedimensional model of the survey site was obtained (Fig. 2,3).

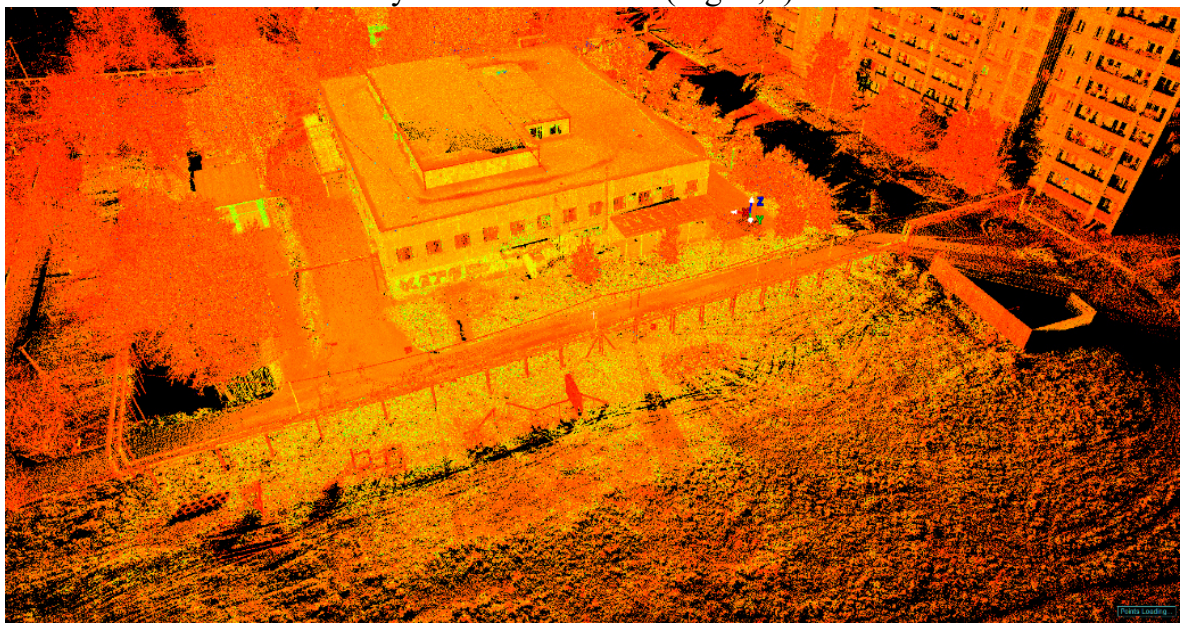

Fig. 2. Fragment of the point cloud of the survey site

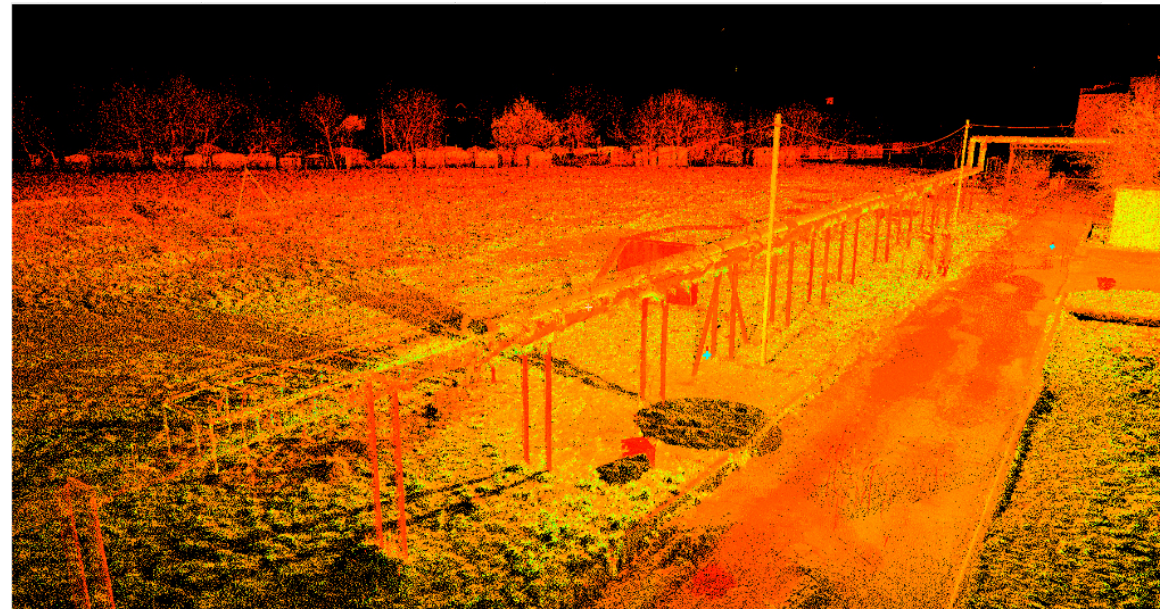

Fig. 3. Fragment of the point cloud of the studied OHPL

Based on this image, strain measurements were taken, the functions and capabilities of existing software were examined, and the possibility of using laser scanning data to diagnose other damage was analyzed.

\section{Results}

An analysis of the literature in the field of overhead line deformations made it possible to 
identify types of monitoring work and classify them with respect to the main structural elements of the power grid facility (Fig. 4).

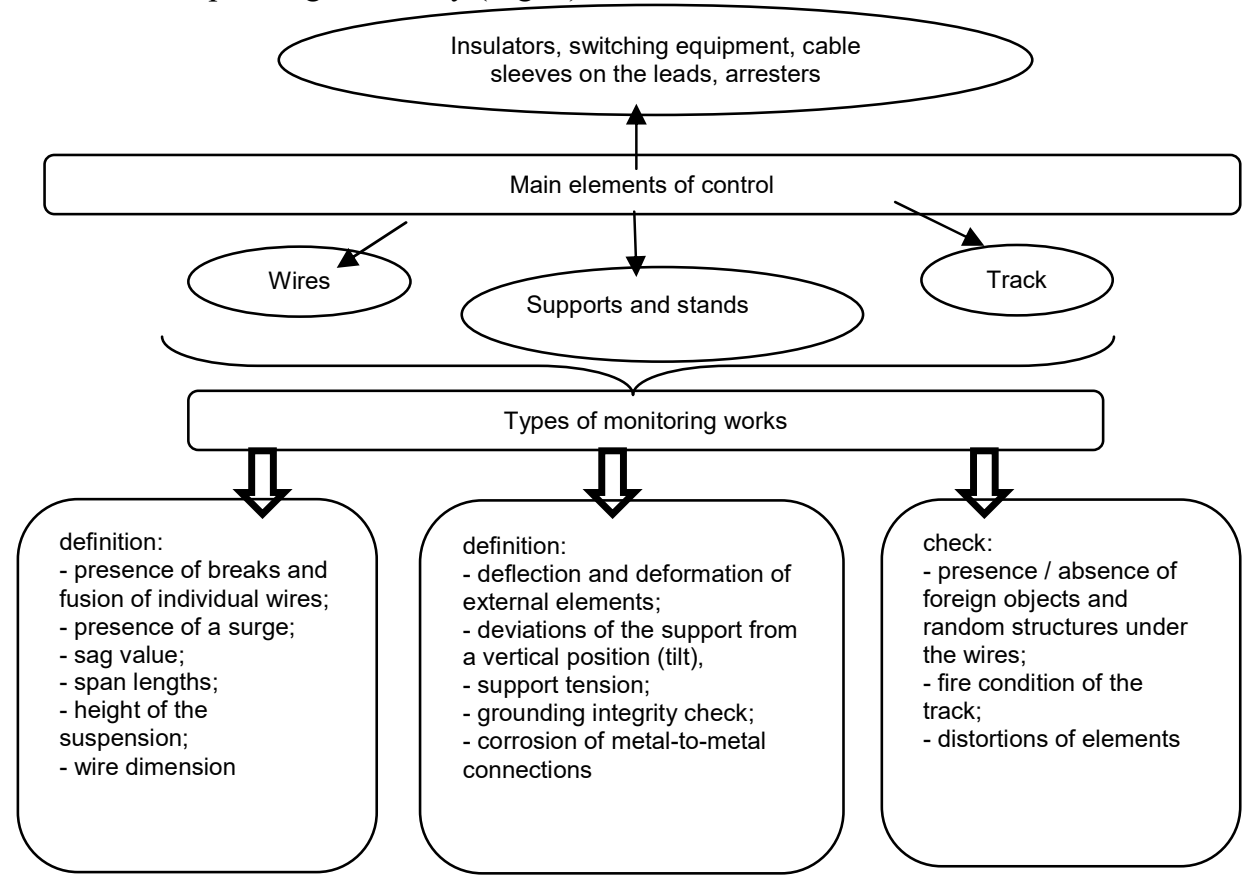

Fig. 4. Scheme of types of work for monitoring the state of overhead power lines

The most thorough inspection, as a rule, is made for the supports and wires. This is due to the fact that the cause of emergency power line shutdowns in the Russian Federation was damage to wires and lightning protection cables (56\%), as well as damage to supports $(15 \%)$ [4]. A review of the literature showed that the greatest attention is paid to the development of methods for determining the deviation of supports from the vertical and the calculation of sagging wires. For this, data can be collected by contact or remotely.

The contact method involves the installation of various sensors, for example, capacitive ones (control of the presence and thickness of the ice wall) installed directly on the contact network [10], weight sensors (ice load value), mounted on a power line support [13], inclinometers of the Leica Nivel 210, Nivel220 type [11]. The latter are high-precision sensors mounted on the supports of high-rise structures for the simultaneous measurement of the slope, its direction and temperature in real time.

The main disadvantage of the method is the additional costs of metrological calibration of sensors, their installation, which is associated with a risk to the life and health of the performer.

The remote methods under consideration can be conditionally divided into three methods according to the instrument used - using a total station, video camera, and laser scanner.

The use of electronic total stations for monitoring structures is widespread. Moreover, the technological range of these devices meets modern requirements. Thus, the use of a robotic total station of Leica TM50 I 0.5", Leica TM50 I 1" type allows automated monitoring by automatically pointing the aiming line of the total station to the selected prism by equipping the visual system with an integrated camera. TargetCapture technology allows the total station to automatically follow the reflector if there are obstacles on the aiming line. A significant disadvantage of this technology is its high cost. 
The second method is sufficiently described in the writings of Shilin A.A., Dementiev S.S. and consists in installing a video camera that fixes the position of the top of the support and the height of the wire with optical marks mounted on it [1]. A significant disadvantage of this method is the analytical calculation of marks' tags.

Laser scanning allows determining the height (Z-coordinate) without additional calculations by a point cloud. In addition, scanning has a number of other advantages [17, 18]:

- linking the collected data to the coordinates of global positioning, which will quickly and efficiently determine the exact location of a structural defect;

- carrying out a survey at a temperature from $0{ }^{\circ} \mathrm{C}$ to $40{ }^{\circ} \mathrm{C}$;

- full performance in absolute darkness and in bright sunlight;

- obtaining a three-dimensional image of deformations.

To conduct a monitoring study, an object was selected in the city of Krasnodar of the Russian Federation - an overhead power line with a voltage of $0.4 \mathrm{kV}$, for which its dimensions were determined using laser scanning data.

According to the results of three-dimensional scanning, the span was determined $27.097 \mathrm{~m}$, sag $-0.847 \mathrm{~m}$, suspension height $-6.040 \mathrm{~m}$, and wire dimension $-5.193 \mathrm{~m}$ (Fig. $5)$.

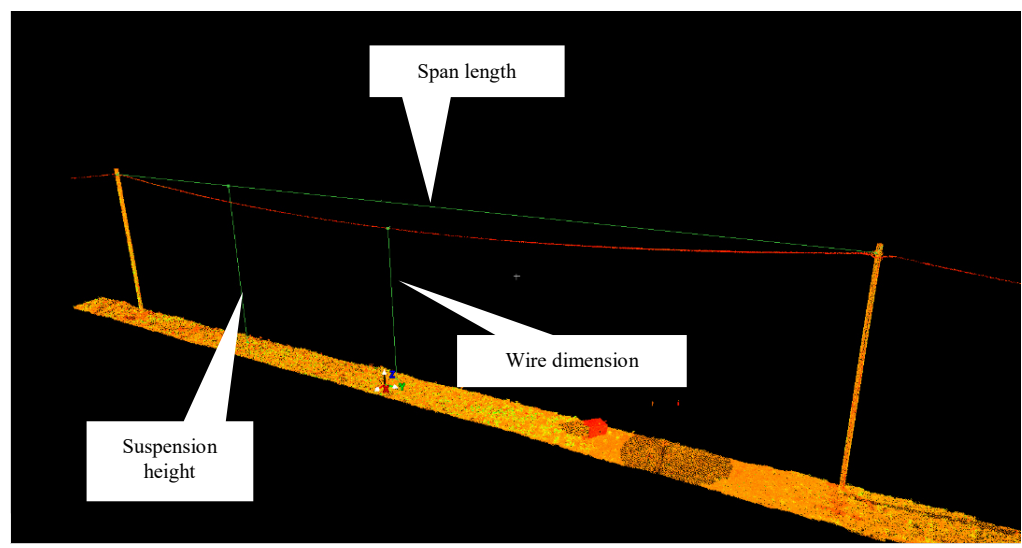

Fig. 5. Determination of the OHPL dimensions according to the results of three-dimensional scanning

In addition to the OHPL dimensions, the deviation of the support from the vertical was determined, which in the considered example was 0.475 degrees (Fig. 6).

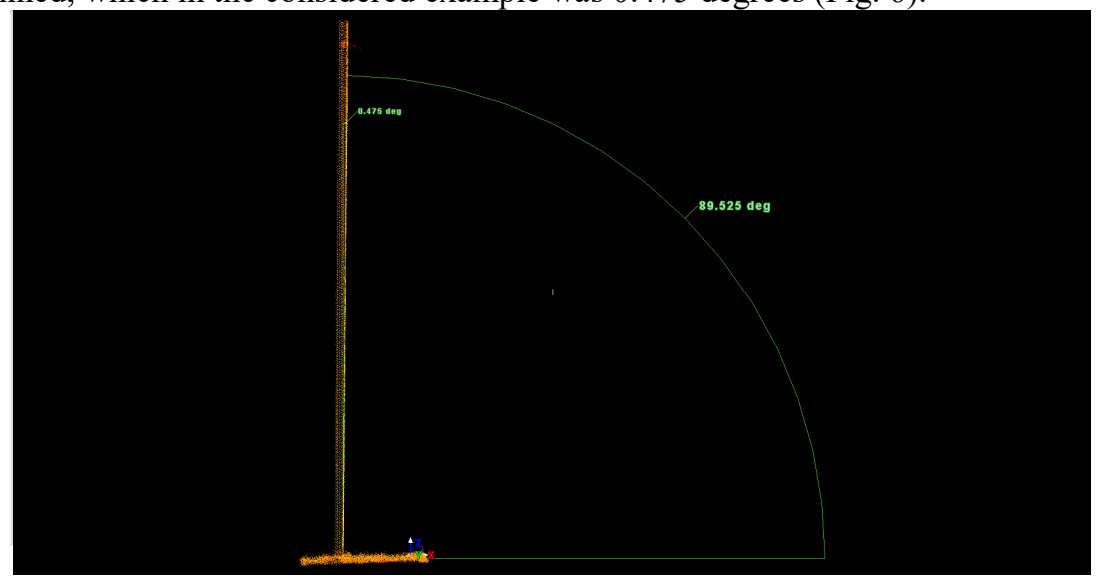

Fig. 6. Determination of deviation of the support from the vertical 
The performed studies show that the data of laser scanning allow monitoring of electric network facilities with obtaining numerical indicators of deformations. However, without systematization and monitoring in a single resource, the method will be ineffective. Therefore, it is proposed to conduct cyclic monitoring with the introduction of the results of three-dimensional measurements in the developed unified digital monitoring urban platform. Strain detection in it can be performed in several ways that define various concepts of a digital platform:

1) according to strain calculation algorithms;

2) compared to real shooting with an ideal model.

In the first case, the following sequence of actions is assumed: import of a stitched and equalized point cloud; the selection of the OHPL structural elements by pressing the appropriate platform command (filtering the scan data will allow detecting strains for each structural part of the object indicated in Figure 3 and the type of strain associated with it); launch of algorithms for the detection and calculation of strain parameters; the issuance and analysis of the result by the operator with the subsequent sending of the team of performers to damaged objects, the coordinates of which are determined in a digital platform.

To implement this concept, it is necessary to develop a classifier of the OHPL structural elements, automate the process of their selection on the basis of machine vision, formalize the search and calculation of deformations, and also upload data on defects and their signs to the database of the proposed digital system.

The implementation of the second concept of the digital platform is to build the ideal model of electric grid facilities and compare it with real data. Such a model will be built on the basis of the location of the OHPL supports and the data of normative and technical documentation.

The algorithm of actions for monitoring deformations in this system is as follows: import of a stitched and equalized point cloud; launching the ideal model; running a command for comparing the ideal and real models and highlighting the differences deformations; calculation of the parameters of certain deformations indicated in Figure 2; delivery and analysis of the result by the operator with the subsequent sending of the team of performers to damaged objects, the coordinates of which are defined in the platform.

\section{Discussion}

The introduction of laser scanning technology in the monitoring system of infrastructure facilities, first of all, will allow:

- carrying out operational collection of objective data on the state of structural elements of power lines and overhead power lines;

- optimizing the process of determining and assessing the main deformations such as tilt of supports, unacceptable sag of wires at the stage of their occurrence.

The timely establishment of deformations will prevent serious accidents, thereby increasing the safety of the operation of engineering infrastructure for the population.

The introduction of a digital monitoring platform with a cyclical update of the scan results will create monitoring conditions in a single analytical and information resource, which will allow analyzing and predicting possible deformations or accidents before they occur on the basis of the results of numerous measurements [19].

\section{Conclusions}

Further research will be devoted to the automation of three-dimensional data processing, namely, the search and calculation of strain parameters using machine vision [16]. The 
research vector will be associated with the development of methods of filtering, image segmentation, pattern recognition, as well as the use of artificial intelligence technology in digital surveys.

In addition, it is planned to further develop and modernize a digital information monitoring platform for other social and engineering infrastructure objects, such as multistory buildings, schools, kindergartens, roads, bridges, and others. The development of the information resource is supposed to be carried out on the basis of distributed registry systems, since monitoring data can be used by various city services [20-22].

The reported study was funded by Russian Foundation for Basic Research and Administration of Krasnodar Region of the Russian Federation according to the research project № 19-48-233020 Study of the possibility of using the complex of three-dimensional laser scanning for monitoring and ensuring the safety of infrastructure facilities in the city of Krasnodar and the Krasnodar Territory

IKNIR AAAA-A18-118121290132-9 "Theory and methods of studying laser scanning data for the management of digital infrastructure"

\section{References}

1. A. Shilin, S. Dementyev. Journal of Instrument Engineering, 61, 490-497 (2018). DOI: $10.17586 / 0021-3454-2018-61-6-490-497$

2. Y. Dubenko, D. Gura, E. Dyshkant. 2019 International Multi-Conference on Industrial Engineering and Modern Technologies (FarEastCon), 1-6 (2019). DOI: 10.1109 / FarEastCon.2019.8934179

3. A. Kwinta, K. Wazydrad, M. Zygmunt. E3S Conf., 55, 00013 (2018). https://doi.org/10.1051/e3sconf/20185500013

4. E. Sokol et al., Electrical Engineering \& Electromechanics, 2, 65-69 (2016). doi: 10.20998/2074-272X.2016.2.12

5. L. Matikainen, M. Lehtomäki, E. Ahokas, J. Hyyppä, M. Karjalainen, A. Jaakkola, A. Kukko, T. Heinonen. ISPRS Journal of Photogrammetry and Remote Sensing, 119, 10 31 (2016). https://doi.org/10.1016/j.isprsjprs.2016.04.011

6. G. Antova. Procedia Earth and Planetary Science, 15, 549-552 (2015). DOI: 10.1016/j.proeps.2015.08.096

7. H. Yang, M. Omidalizarandi, X. Xu, I. Neumann. Composite Structures, 169, 173-179 (2017). DOI: 10.1016/j.compstruct.2016.10.095

8. L. Li. Proceedings of the International Conference on Advances in Mechanical Engineering and Industrial Informatics, 1542-1545 (2015). doi: 10.2991/ameii15.2015.285.

9. M. Lehtomäki, K. Antero, L. Matikainen, J.Hyyppä, H.Kaartinen, A. Jaakkola. Automation in Construction, 105 (2019). https://doi.org/10.1016/j.autcon.2019.03.023

10. N. Mao, M.Guoming, C. Li, Y. Li, C. Shi, Y. Du. Proc. SPIE 10323, 25th International Conference on Optical Fiber Sensors, 10332359, (2017). doi: 10.1117/12.2267470.

11. M. Goryachev, M. Sadykov, D. Yaroslavskiy. Power engineering: research, equipment, technology., 21, 160-171 (2019). doi: 10.30724/1998-9903-2019-21-3-160-171.

12. E. Kabalci, Y. Kabalci. Measurement science review, 13, 248-252 (2013). DOI: 10.2478/msr-2013-0037.

13. R. Wachal et al. PES T\&D 2012, 1-6 (2012) DOI: 10.1109/TDC.2012.6281621 
14. G.Römer, P.Bechtol. Physics Procedia, 56, 29-39 (2014). https://doi.org/10.1016/j.phpro.2014.08.092

15. B. Farahani, F. Barros, P. Sousa, P.Cacciari, P. Tavares, M. Futai, P. Moreira. Tunnelling and Underground Space Technology 91, 102995, (2019). https://doi.org/10.1016/j.tust.2019.102995

16. D.Gura, Y.Dubenko, G. Shevchenko, E. Dyshkant, N. Khusht. Transportation Soil Engineering in Cold Regions, 2, 185-190 (2020). https://doi.org/10.1007/978-981-150454-9_19

17. D. Gura, Y. Dubenko, E. Dyshkant, A. Pavlyukova, G. Akopyan. IOP Conference Series: Earth and Environmental Science, 403 (2019). DOI: 10.1088/1755$\underline{1315 / 403 / 1 / 012184}$

18. D. Gura, Y. Dubenko, I. Markovskiy, S. Pshidatok. IOP Conference Series: Earth and Environmental Science, 403 (2019). DOI: 10.1088/1755-1315/403/1/012185

19. V. Shishkina, D. Gura, I. Gribkova, M. Bykova. IOP Conference Series: Materials Science and Engineering, 698(6), 066016 (2019). DOI: 10.1088 / 1757-899X / $\underline{698 / 6 / 066016}$

20. G. Barsukova, K. Shumaeva. Moskovski Economicheskiy Zhurnal, 4, 14-22 (2019). DOI: $10.24411 / 2413-046 \mathrm{X}-2019-14013$

21. M. Ananin, N. Perfilyeva, I. Vedishcheva, N. Vatin, IOP Conference Series: Materials Science and Engineering 365(2) (2018). DOI:10.1088/1757-899X/365/2/022014.

22. A.K. Baiburin, M.M. Rybakov, N.I. Vatin, Magazine of Civil Engineering 85(1), 3-14 (2019). DOI:10.18720/MCE.85.1. 